\title{
Hormone Antagonist
}

National Cancer Institute

\section{Source}

National Cancer Institute. Hormone Antagonist. NCI Thesaurus. Code C547.

Substances that inhibit or antagonize the function of the endocrine glands, the biosynthesis or biological effect of secreted hormones. 